\title{
ПОНЯТИЕ БЛАГОТВОРИТЕЛЬНОЙ ДЕЯТЕЛЬНОСТИ И ЕЕ РАЗВИТИЕ В РОССИИ
}

\author{
(c) 2020 Ибрагимов Юсуп Муслимович \\ ассистент кафедры теории и технологии социальной работы \\ Чеченский государственный университет, Чеченская Республика, Грозный \\ E-mail yusuf_ibr@mail.ru \\ (c) 2020 Майрбеков Султанбек Саламуевич \\ Студент-магистрант юридического факультета \\ Чеченский государственный университет, Чеченская Республика, Грозный \\ E-mail: berserk955@mail.ru
}

В статье рассматривается одна из актуальных для российского общества проблем - развитие благотворительности, выявление основных проблем и поиск их решения. Прослеживаются исторические аспекты возникновения благотворительной деятельности. Показаны правовые аспекты работы организаций, занимающихся благотворительностью.

Ключевые слова: благотворительность, помощь, гражданское общество, государственность.

Формирование гражданского общества в России сопровождается повышением общественной активности. Государство, пытаясь решать социальные проблемы, в настоящее время стоит перед необходимостью привлечения к этому процессу негосударственных организаций, в том числе благотворительных. Уход от государственной монополии в производстве, торговле, финансовой сфере способствовал развитию благотворительного движения в социальной сфере.

Желанной, а на некоторых этапах развития даже необходимой формой отношений людей, заинтересованных в упорядоченности интересов и возможности влиять на решение проблем общества и конкретной личности, в частности, является благотворительность. Поэтому перед наукой стоит задача не только урегулировать правоотношения, связанные с благотворительной деятельностью, но и показать широкий спектр направлений ее возможного применения.

Вопрос происхождения благотворительности, ее значение в разных исторических эпохах и систем общественных отношений, эволюция благотворительной деятельности и ее форм, соотношение понятий «благотворительность», «благотворительность», «благотворительная деятельность» и «меценатство» до сих пор остаются дискуссионными. В научных кругах не пришли к единому или признанной большинством мнения относительно этой научной и общественной проблемы. Например, ученыйисторик Е.М.Михеева считает, что благотвори- тельная деятельность является, с одной стороны, формой общественных отношений в рамках гражданского общества, а с другой - социокультурным феноменом своего времени [10].

Проявления благотворительности в России существовали издавна, постепенно перерастая в устоявшиеся традиции, живших веками и переходили из поколения в поколение как лучшие достижения человечества. Считается, что истоки благотворительной деятельности восходят к временам принятия христианства и становления российской государственности [5]. До конца XVII в. благотворительной деятельностью занималась в основном церковь. Позже благотворительностью стали заниматься цари. Царь Алексей Михайлович, правивший Русью с 1645 года по 1676 год, в дни религиозных праздников раздавал продукты и деньги не только нищим, но и заключенным в тюрьмах. В 1862 году царем Федором Алексеевичем был издан указа об открытии приютов и богаделен, но история умалчивает, были ли они тогда созданы или нет. Что касается Петра I, то он вовсе запретил просить милостыню, за это было предусмотрено наказание, а больных и немощных помещали в богадельни. Положение изменилось, когда пришла к власти Екатерина II, которая возродила древнюю российскую традицию покровительства благотворительности с участием в ней правителей. В целом вплоть до революции 1917 года цари Руси оказывали покровительство благотворительной деятельности, а во второй половине XIX века 
благотворительностью стали заниматься представители многих династий купцов и фабрикантов. История российского народа свидетельствует о фактах милосердия и благотворительности, как проявления высоких моральных качеств и этических норм, которые характеризуют общественные приоритеты.

В последнее время развитие благотворительного движения и благотворительная деятельность отдельных лиц и семей привлекают все большее внимание ученых, поскольку благотворительность остается важным аспектом жизни страны и отношений между государством и гражданским обществом.

Понятие «благотворительность» вошло в общественное сознание как гуманистический призыв человека оказывать помощь нуждающимся независимо от национальной, расовой, социальной, религиозной принадлежности. Практика благотворительной помощи и новейшие исследования общественных наук показали, что моральные основания благотворительности не противоречат религиозным канонам одной из трех мировых религий. А христианство рассматривают как идейный источник благотворительности.

Сейчас такая деятельность приобретает все большее значение в решении острых социальных проблем - благотворительные организации, фонды вносят значительный вклад в социальную сферу. В понятие «благотворительность» современное общество вкладывает широкий смысл - от обычной материальной помощи до меценатства.

Итак, благотворительность можно трактовать как некоммерческую деятельность организаций и физических лиц, направленную на удовлетворение потребностей социального развития. В более широком понимании благотворительность определяется как «инвестирование социальной сферы».

В историко-правовой литературе начала $\mathrm{XX}$ века не имеет достаточно полного определения благотворительности. Как правило, ее рассматривают через призму одной или нескольких присущих ей признаков. Например, Д.Страховский считает ее «... проявлением сочувствия к ближнему», Г. Ульгорн - «... бескорыстной помощью нищим». Доктор Айван Шевер говорит, что «благотворительность является принудительных, базируется на стремлении помочь. Это дело, сделанное без предварительной мысли о финан- совом вознаграждении». Самый популярный российский Энциклопедический словарь Брокгауза и Ефрона определяет благотворительность как «проявление сострадания к ближнему и нравственную обязательность имущего спешить на помощь неимущему ...». Толковый словарь В.Даля характеризует личность благотворителя как «творящего, делающего добро другим». По мнению итальянского ученого Нуово Дизионарио, «благодетель - это гражданин, добровольно, а не для того, чтобы продемонстрировать свои материальные обязательства или законные обязанности, руководствуется идеей общественной и частной солидарности» [11].

Недостатком всех этих определений является то, что они не дают целостного представления о благотворительности, а лишь воспроизводят определенную сторону одного явления. По объективным содержанием понятия «благотворительность» достаточно близко к милосердию, однако рассматривать его просто как проявление последнего было бы неправомерно, поскольку в своей экзистенциальной основе они необязательно совпадают, хотя милосердие можно определить, как деятельное стремление помочь каждому, кто в этом имеет потребность. Как благотворительность, так и милосердие, имеет высокую этическую ценность, моральная стоимость которой незаменима. Чтобы оставаться на присущей им нравственной высоте, они должны сочетаться с уважением к каждому адресату, иначе будет потеряно их положительный духовный смысл.

Исторически сложились три вида благотворительности: личная, общественная и государственная. Первую осуществляют физические лица. Вторая является формой организованной благотворительности и формой общественной опеки, то есть благотворительной деятельности отдельных общин. Третья - благотворительная деятельность государства [14].

Среди самых распространенных видов современной отечественной благотворительности - организованная (общественная), осуществляемая благотворительными организациями. Анализ норм Закона от 11.08.1995 № 135-Ф3 «О благотворительной деятельности и благотворительных организациях» дает возможность сделать вывод, что благотворительности характерны: бескорыстие, добровольность, осознанность и целевой характер. Согласно этому закону, благотворительность - добровольное 
бескорыстное пожертвование физических и юридических лиц в предоставлении приобретателям материальной, финансовой, организационной и другой благотворительной помощи. Специфическими формами благотворительности является меценатство и спонсорство. В ноябре 2014 года принят федеральный закон «О меценатской деятельности» [4], который под меценатской деятельностью понимает деятельность по безвозмездной передаче имущества, в том числе денежных средств, или прав владения, пользования, распоряжения имуществом и (или) безвозмездные выполнение работ и оказание услуг в сфере культуры и образования в области культуры и искусства, направленные на сохранение культурных ценностей и развитие деятельности в сфере культуры и образования в области культуры и искусства. Что касается понятия «спонсорство», то его можно найти в Законе «О рекламе» [2], где в п. 9 статьи 3 говорится, что спонсором является лицо, которое предоставило средства или же обеспечило предоставление средств для организации и (или) проведения спортивного, культурного или любого иного мероприятия, создания и (или) трансляции теле- или радиопередачи либо создания и (или) использования иного результата творческой деятельности.

Спонсорство - один из способов рекламирования не только бренда, но и продукции, это эффективный PR-инструмент. На сегодняшний день очень престижно быть инвестором в части финансовой поддержки различного рода спортивных, культурно-массовых, иных творческих мероприятий, в том числе выступать в качестве спонсора различных концертов, выставок и т.п.

Именно направленностью своих целей спонсорство отличается от благотворительности. Кроме того, благотворительность, в отличие от спонсорства, может быть анонимной [17].

В последние годы развивается ещё одна форма благотворительности, это - волонтерство. Волонтерство многие авторы называют добровольной формой благотворительности [16]. Волонтерство называют широкий круг деятельности, которые включает традиционные формы взаимопомощи и самопомощи, официальное предоставление услуг и другие формы гражданского участия, которая осуществляется добровольно на благо широкой общественности безвозмездно.

Следующей формой благотворительной де- ятельности можно считать сетевую благотворительную деятельность. Масштаб охвата сети интернет достиг практически всех видов человеческой деятельности, в т.ч. и благотворительности. Интернет-пространство сегодня является важным фактором, модернизирующим такое явление современного общества как благотворительность. Тенденция возникновения новых форм благотворительности, вызвана к жизни процессами трансформации ценностносмысловой составляющей общественного сознания населения. В работе «Традиционные и инновационные формы благотворительности в России» Н. Н. Пешкова приводит классификацию, относя к инновационным такие формы, как эндаумент, фандрайзинг, спонсоринг, венчурная благотворительность и социальное служение [15].

Эндаументом (от англ. endowment - снабжение, вклад) или эндаумент-фондом называется целевой фонд, который создается для некоммерческих целей, в частности, для финансирования организаций образования, культуры, медицины и т.п. Финансирование эндаумента производится в основном за счет благотворительных пожертвований.

Правовое регулирование эндаумента в Российской Федерации регулируется рядом федеральных законов. В частности, статьей 582 ГК РФ, которая регулирует правила пожертвования; статьей 437 ГК РФ, которая регламентирует публичный сбор денежных средств для целевого капитала; главой 53 ГУ РФ, которая регулирует доверительное управление имуществом и другим статьи ГК РФ. Кроме ГК РФ, эндаумент регулирует Налоговый кодекс Российской Федерации, который освобождает от налога эндаумент (пп. 8 п.2 ст.146 НК РФ). Ввиду того, что эндаумент деятельность только некоммерческих организаций, то он регулируется и федеральным законом, который регулирует деятельность некоммерческих организаций. Поскольку средства на эндаумент - это средства на формирование целевого капитала некоммерческих организаций, то эндаумент регулируется и Федеральным законом «О порядке формирования и использования целевого капитала некоммерческих организаций» [3]. Что касается Закона о благотворительной деятельности, то в нём нет норм, которые урегулировали бы эндаумент.

Фандрайзинг (Fundraising) - это привлечение материальных и финансовых средств для реализации проектов (не только волонтерских, 
но и благотворительных), для помощи нуждающимся. Регулируется главой 54 ГК РФ, которая устанавливает правила коммерческой концессии и Федеральным законом «О порядке формирования и использования целевого капитала некоммерческих организаций». Закон о благотворительной деятельности не содержит норм, которые урегулировали бы фандрайзинг.

Спонсоринг (англ. sponsoring, sponsorship поддержка, поручительство) обязательно предполагает получение определенной выгоды для спонсора, которая не всегда просчитывается и выражается в деньгах. В бизнесе этот термин трактуется как организация самого мероприятия, контроль за его проведением, PR-обеспечение и реклама. Этот вид благотворительной деятельности пока не урегулирован российским законодательством.

Венчурной благотворительностью называется помощь юридическим лицам в их деятельности, стимулирование к развитию. Этот вид благотворительной деятельности также пока не урегулирован российским законодательством.

Социальным служением называют деятельность религиозных организаций, направленных на смягчение остроты социальных проблем. Этот вид деятельности регулируется статье 18 Федерального закона «О свободе совести и о религиозных объединениях» [1], где сказано, что религиозные организации могут осуществлять благотворительную деятельность.

K этому списку инновационных форм также следует отнести краудфандинг, получивший сегодня большое распространение. Краудфандинг - это коллективное сотрудничество людей, которые добровольно объединяют свои денежные средства или иные ресурсы вместе, чтобы поддержать усилия других людей или организаций [7]. Как правило, сбор средств осуществляется в сети интернет. Стоит отметить, что сетевая благотворительность на сегодняшний день выступает в качестве значимого и действенного ресурса. Это обусловлено, в первую очередь, удобством данной формы. В связи с ускоренным ритмом жизни современного человека остро проявляется дефицит свободного времени. В качестве основных инструментов сетевой благотворительности сегодня выступают сайты помощи, форумы различной тематической направленности и социальные сетевые сообщества.

Принятие Закона от 11.08.1995 № 135-ФЗ, в котором термин «благотворительность» опреде- лено как «добровольная деятельность граждан и юридических лиц по бескорыстной (безвозмездной или на льготных условиях) передаче гражданам или юридическим лицам имущества, в том числе денежных средств, бескорыстному выполнению работ, предоставлению услуг, оказанию иной поддержки».

Исходя из законодательного определения благотворительности можно вывести её признаки: добровольность и бескорыстность. Если с первым признаком проблем не возникает, что со вторым признаком благотворительности - с бескорыстностью не всё ясно. Под бескорыстностью Закон от 11.08.1995 № 135-ФЗ понимает не только оказание поддержки на безвозмездной, но и льготной основе. Таким образом, включение словосочетания «на льготных условиях» несколько исказило первоначальное этимологическое значения понятия «бескорыстность». По словарю С.И. Ожегова, бескорыстность - отсутствие корыстных интересов [12]. Получение льготных условий вряд ли может считаться отсутствием корыстных интересов. Сам Закон от 11.08.1995 № 135-Ф3 не раскрывает понятия бескорыстности. В частности, неясно, будет ли являться благотворительностью реализация товаров по пониженным ценам некоммерческой организации или выполнение работ, при которых заказчик (к примеру, религиозная организация) оплачивает лишь стоимость материалов, а работы исполнитель оказывает безвозмездно. Вполне вероятно, что получение любых доходов от граждан или организаций проверяющие расценят как основание для начисления налога на добавленную стоимость без права на применение льготы.

Разъяснения контролирующих органов по данному вопросу отсутствуют. Арбитражной практики также найти не удалось. Представляется, что при таких обстоятельствах наличие слова «бескорыстной» в Законе от 11.08.1995 № 135-ФЗ излишне. Предлагаем ст. 1 Закона от 11.08.1995 № 135-ФЗ изложить в следующей редакции: «Под благотворительной деятельностью понимается добровольная деятельность граждан и юридических лиц по безвозмездной или на льготных условиях... далее - по тексту».

А.А. Кумаритова отмечает, что добровольность означает осуществление благодетелем своей деятельности на основании собственного волеизъявления без какого-либо принуждения со стороны других лиц [8]. По мнению А. В. Кости- 
на, жертвовательская деятельность благодетеля заключается в непринужденном осознанном неполучении (недополучении) им указанного материального эквивалента или тех прав, которые необходимы самому благотворителю. Наряду с сознательным отношением к благотворительности, жертвовательская деятельность благотворителей чаще всего связана с передачей приобретателю помощи того материального объекта или тех прав, которые необходимы самому благотворителю. Действительно, если в основе неосознанного бескорыстия лежит добровольное пожертвование избытка, то есть того объекта или иных прав, которые выходят за пределы необходимых потребностей благодетеля, то жертвовательская деятельность предусматривает добровольное аскетическое самоограничение благодетеля: он без всякого принуждения жертвует то, что нужно ему самому [6].

Возвращаясь к определениям категорий «благотворительность», «благодетельство» и «благотворительская деятельность», констатируем, что современное законодательство РФ о благотворительности основывается на определенной этической концепции. Источники ее были заложены еще каноническим правом, определяющим признаком благотворительности считало характер личных побуждений благотворителя к совершаемых благодеяний. Согласно классическим представлениям безупречность побуждений благотворителей к осуществляемой ими деятельности имела важное значение. Отсутствие «добрых» намерений благодетеля, который оказывал благотворительную помощь не бескорыстно, а имея меркантильные цели, отрицало моральную ценность такой помощи, порождая тем самым кажущуюся благотворительность [9].

Сравнительный анализ «благотворительность», «благодетельство» и «благотворительская деятельность» свидетельствует, что, например, благодетельство является частной акцией по оказанию помощи, нуждающимся со стороны физических и юридических лиц (не являются благотворительными организациями), а благотворительная деятельность - это регулярная деятельность с целью оказания благотворительной помощи, осуществляемой благотворительными организациями. Понятие «благотворительность» сочетает в себе благодетельство и благотворительную деятельность, поэтому по содержанию оно шире двух последних понятий. Их роднит общая цель: и благотворительность, и благотво- рительная деятельность осуществляются с целью предоставления благотворительной помощи [13].

По нашему мнению, благотворительность - это добровольная, осознанная, безвозмездная или на льготных условиях деятельность организованных субъектов (благотворительных объединений) и одноразовое или периодическое действие отдельных благотворителей, направленные на улучшение социального положения определенных лиц, которые в этом нуждаются, и решения проблем социально- культурной сферы общества в целом. А благодетельство - это добровольная, безвозмездная, осознанная жертва, осуществляемая в форме финансовой, материальной, организационной помощи или оказанной услуги, с целью улучшения материального и морального состояния ее приобретателя. Такое определение точнее воспроизводит значение этого понятия, потому что указывает на то, что благотворительность - это конкретное действие, осуществление в отношении другого лица, которое имеет в этом потребность. В то же время благотворительная деятельность - это добровольная, безвозмездная или на льготных условиях, осознанная, неприбыльная экономическая деятельность организованных субъектов по предоставлению финансовой, материальной, организационной помощи ее приобретателям, а также бесплатного предоставления услуг по ее осуществлению, с целью улучшения материального и морального состояния отдельных лиц и социально-экономического развития. Иначе говоря, благотворительную деятельность можно трактовать как особый вид социальных отношений, которые возникают между юридическими и физическими лицами и государством при формировании и использования благотворительных средств, предоставления материальной, организационной помощи, а также социальных услуг с целью улучшения реализации конституционных прав граждан на охрану здоровья, образование, социальную защиту, культурное развитие и обеспечение общественного благосостояния в целом.

Таким образом, законодательное определение благотворительной деятельности не в полной мере отражает сущность благотворительной деятельности. Исследование показало, что применение термина «бескорыстность» противоречит оказанию благотворительной деятельности на льготных условиях. Полагаем, что благотво- 
рительной деятельностью является добровольная деятельность граждан и юридических лиц по безвозмездной или на льготных условиях передаче нуждающимся имущества, включая денежные средства, бескорыстное выполнение работ, предоставление услуг, оказание иной поддержки.

\section{Библиографический список}

1. Федеральный закон от 26 сентября 1997 г. № 125-Ф3 (в редакции от 02 декабря 2019 г.) «О свободе совести и о религиозных объединениях» // СЗ РФ.1997. № 39. Ст. 4465.

2. Федеральный закон от 13.03.2006 № 38-Ф3 (ред. от 31.07.2020) «О рекламе» // СЗ РФ. 2006. № 12. Ст. 1232.

3. Федеральный закон от 30 декабря 2006 г. № 275 -ФЗ (в редакции от 31 июля 2020 г.) «О порядке формирования и использования целевого капитала некоммерческих организаций» // СЗ РФ.2007. № 1 (1 ч.). Ст. 38.

4. Федеральный закон от 4 ноября 2014 г. № 327-ФЗ «О меценатской деятельности» // СЗ РФ. 2014. № 45. Ст. 6137.

5. Бякина В.П., Качалова В.Г. Благотворительность и меценатство в Российской Империи (XVIII-XIX вв.) // Ученые записки Санкт-Петербургского имени В.Б.Бобкова филиала Российской таможенной академии. 2011. № 3 (40). С. 184.

6. Костин А.В. Институт доверительной собственности (траст) в сфере общественно-благотворительной деятельности в английском праве // Иностранное право. Сборник научных статей и сообщений.- М.: МАКСПресс, 2002, Вып. 3.- С. 142-153

7. Краудфандинг. [Электронный ресурс] // https://ru.wikipedia.org/wiki

8. Кумаритова А. А. Гражданско-правовое положение некоммерческих организаций в сфере благотворительной деятельности. Автореф. дис. ... канд. юрид. наук / Кумаритова А.А.- М., 2006. - С.12

9. Мельников В.С. Правовое регулирование благотворительной деятельности в России // Россия и мир: вчера, сегодня, завтра. Российское законодательство и проблема его совершенствования.- М.: Изд-во МГИ им. Е.Р.Дашковой, 2006.- С. 38-58

10. Михеева Е.М., Михеева Н.Н. Благотворительная деятельность и правосознание населения // Традиция. Духовность. Правосознание. Материалы Всероссийской научной конференции, 12-13 мая 2006 г..- Тюмень: Тюм. юрид. ин-т МВД РФ, 2006. - С. 107-110

11. Нечаева М.А. Благотворительная деятельность в современной России: особенности концептуализации и приоритеты развития в национальном правовом пространстве // Научные труды РАЮН. Вып. 11. В 2 т. Т. 1.- М.: Юрист, 2011.- С. 437

12. Ожегов С. И. Толковый словарь русского языка. - М.: Мир и образование, 2013.- С. 707.

13. Пашенцева С.В. Правовое регулирование благотворительной деятельности в Российской империи // Государство и право. 2006. № 12.- С. 98-104

14. Писенко К.А. Правовые аспекты благотворительной деятельности и социального служения Русской Православной Церкви // Актуальные проблемы российского и зарубежного права. Материалы научной конференции аспирантов кафедры гражданского и трудового права РУДН. Москва, 25 января 2002 г.- М.: Статут, Изд-во РУДН, 2003.- С. 254-264

15. Пешкова Н.Н. Традиционные и инновационные формы благотворительности в России // Омский научный вестник. 2011. № 101. С. 43-46.

16. Пушкарёва Т.В., Мельникова В.Н. Волонтерство как добровольная благотворительная деятельность // Вестник Костромского государственного университета им. Н.А.Некрасова. 2013. Т. 19. № 1. С. 188-190; Юдин И. Волонтерство в правовом аспекте // Особенности формирования правовой культуры российского общества в XXI в.: сборник научных трудов.- Липецк: ООО «Принт Мастер», 2013. С. 87-90.

17. Стюфеева И. В. Благо надо творить // СПС КонсультантПлюс. 2013. 